\title{
E-cadherin expression pattern during zebrafish embryonic
}

\section{epidermis development [version 1; peer review: 1 approved, 2}

\section{approved with reservations]}

\author{
María Florencia Sampedro1,2, María Fernanda Izaguirre (iD), Valeria Sigot (iD) 1,2 \\ ${ }^{1}$ Laboratorio de Microscopía Aplicada a Estudios Moleculares y Celulares (LAMAE), Facultad de Ingeniería, Universidad Nacional de \\ Entre Ríos, Oro Verde, 3100, Argentina \\ ${ }^{2}$ Instituto de Investigación y Desarrollo en Bioingeniería y Bioinformática (IBB-CONICET- Universidad Nacional de Entre Ríos), Oro \\ Verde, 3100, Argentina
}

V1 First published: 18 Sep 2018, 7:1489

https://doi.org/10.12688/f1000research.15932.1

Second version: 13 Dec 2018, 7:1489

https://doi.org/10.12688/f1000research.15932.2

Latest published: 18 Feb 2019, 7:1489

https://doi.org/10.12688/f1000research.15932.3

\section{Abstract}

Background: E-cadherin is the major adhesion receptor in epithelial adherens junctions (AJs). On established epidermis, E-cadherin performs fine-tuned cell-cell contact remodeling to maintain tissue integrity, which is characterized by modulation of cell shape, size and packing density. In zebrafish, the organization and distribution of Ecadherin in AJs during embryonic epidermis development remain scarcely described.

Methods: Combining classical immunofluorescence, deconvolution microscopy and 3D-segmentation of AJs in epithelial cells, a quantitative approach was implemented to assess the spatial and temporal distribution of E-cadherin across zebrafish epidermis between 24 and 72 hpf.

Results: increasing levels of E-cadh protein parallel higher cell density and the appearance of hexagonal cells in the enveloping layer (EVL) as well as the establishments of new cell-cell contacts in the epidermal basal layer (EBL), being significantly between 31 and $48 \mathrm{hpf}$. Conclusions: Increasing levels of E-cadherin in AJs correlates with extensive changes in cell morphology towards hexagonal packing during the epidermis morphogenesis.

Keywords

Key words: E-cadherin; adherens junctions; zebrafish epidermis; enveloping layer (EVL), epidermis basal layer (EBL), deconvolution, 3D segmentation

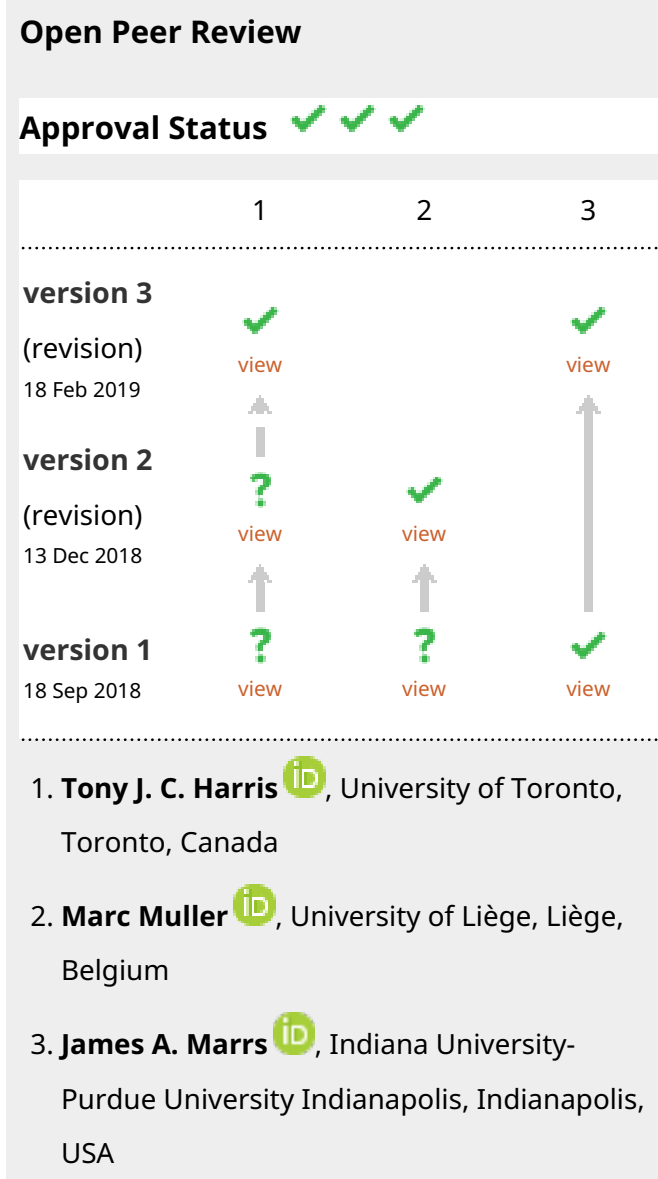

Any reports and responses or comments on the article can be found at the end of the article. 
Corresponding authors: María Fernanda Izaguirre (fizaguirre@ingenieria.uner.edu.ar), Valeria Sigot (vsigot@ingenieria.uner.edu.ar)

Author roles: Sampedro MF: Data Curation, Formal Analysis, Methodology, Software, Visualization, Writing - Original Draft Preparation, Writing - Review \& Editing; Izaguirre MF: Conceptualization, Data Curation, Funding Acquisition, Investigation, Methodology, Project Administration, Validation, Visualization, Writing - Original Draft Preparation; Sigot V: Conceptualization, Data Curation, Formal Analysis, Funding Acquisition, Investigation, Methodology, Project Administration, Resources, Software, Supervision, Validation, Visualization, Writing - Original Draft Preparation, Writing - Review \& Editing

Competing interests: No competing interests were disclosed.

Grant information: This work was supported by the National University of Entre Ríos, Argentina [PID-UNER 6145].

The funders had no role in study design, data collection and analysis, decision to publish, or preparation of the manuscript.

Copyright: (c) 2018 Sampedro MF et al. This is an open access article distributed under the terms of the Creative Commons Attribution License, which permits unrestricted use, distribution, and reproduction in any medium, provided the original work is properly cited. Data associated with the article are available under the terms of the Creative Commons Zero "No rights reserved" data waiver (CC0 1.0 Public domain dedication).

How to cite this article: Sampedro MF, Izaguirre MF and Sigot V. E-cadherin expression pattern during zebrafish embryonic epidermis development [version 1; peer review: 1 approved, 2 approved with reservations] F1000Research 2018, 7:1489

https://doi.org/10.12688/f1000research.15932.1

First published: 18 Sep 2018, 7:1489 https://doi.org/10.12688/f1000research.15932.1 


\section{Introduction}

The skin is the largest organ of the body in direct contact with the environment. It has a complex structure, being constituted by many different tissues. Skin performs functions that are vital in maintaining body homeostasis, such as the control of body temperature and protection from physical damage and bacterial invasion. Sensory axons innervate the skin at early developmental stages enabling the embryo to sense mechanical, thermal, and chemical stimuli ${ }^{1}$.

In particular, the topology -connectivity, continuity and neighborhood-, and individual cell phenotypes of epidermis define the strength and permeability of the protective barrier between the organism and its environment. Although epidermis structure varies between aquatic and terrestrial organisms, its stratification is a common mechanism during development ${ }^{2}$.

\section{Epidermis development in zebrafish (Danio rerio)}

In zebrafish, the prospective epidermis establishes soon after the end of gastrulation, constituted by the surface layer, enveloping layer (EVL), and the inner epidermal basal layer (EBL) ${ }^{3,4}$. EVL arises at mid-blastula stage (2.5 hours post fertilization; hpf) covering the whole embryo ${ }^{5}$. During epiboly EVL maintains tight joins to the yolk syncytial layer (YSL), and becomes the migration substrate for the underlying deep cells spreading during gastrulation ${ }^{6}$. At the tail bud stage (8-10 hpf), the epiblast forms the outer germ layer, the ectoderm, characterized as a pseudo-epithelial germ layer. From the non-neural ectoderm arises the EBL, which covers the whole embryonic surface underneath the EVL to form a two-layered epithelium by $10 \mathrm{hpf}$. At $24 \mathrm{hpf}$, the epidermis is a distinctive bilayer in which the basal layer actively produces collagen to form the basal membrane and the primary dermal stroma ${ }^{7,8}$. It is after three weeks that the epidermis becomes further stratified and develops into the adult teleost four-layered epidermal structure: cuticle, surface, intermediate and basal stratums ${ }^{9}$. In adult zebrafish, the EVL cells are replaced by those derived from basal keratinocytes $^{8}$. Thus, the epidermis of adult zebrafish, as in mice, derives from basal stem cells, further expanding the similarities of epidermal ontogeny across vertebrates ${ }^{10}$.

\section{The importance of studying E-cadh in epidermis}

E-cadh is member of a superfamily of cadherins, calciumdependent cell-cell adhesion molecules forming junctions along the apicolateral membranes of adjacent cells ${ }^{11-13}$. E-cadh plays a key role in determining cell polarity and differentiation, and thereby in the establishment and maintenance of metazoan tissue homeostasis ${ }^{2,14}$. As epithelia are constituted by cell phenotypes with the maximum polarity and whose identity is primarily specified by E-cadh, it is key to know its expression in the epidermis establishment and maintenance ${ }^{15}$. Furthermore, due to the mechano-transduction activity coupled to the acto-myosin cytoskeleton remodeling, E-cadh is involved in processes such as cell division orientation in planar polarized epithelia ${ }^{15}$ and collective cell migration ${ }^{16}$. Relevant as well is that E-cadh has been characterized as a potent suppressor of invasion and metastasis in epithelia ${ }^{17}$, which are usually located in direct contact with mutagenic and/or carcinogenic agents responsible for $85-90 \%$ of human cancers ${ }^{18}$.
In zebrafish, E-cadh transcripts and proteins are maternally deposited. Reduced levels of the maternal and zygotic protein has been proved to delay epiboly progression with lethal phenotypes $^{5}$. E-cadh is required for blastomeres adhesion during the cleavage stage and later during gastrulation and epiboly ${ }^{19-21}$. Indeed, as epiboly proceeds, EVL directs cell migration and the spreading of cells of the deep cells layer (DCL) in a process that requires dynamic cell contacts remodeling mediated by E-cadh ${ }^{6}$. Once the bi-layered epidermis is established, E-cadh role becomes more refined by keeping its integrity while actively remodeling cell-cell contacts within each layer. At tissue scale, this leads to cell rearrangements which establish regular geometric patterns, and loss of E-cadh results in altered epidermis topology $y^{5,14,22}$. Strikingly, scarce knowledge exists regarding epidermal spatiotemporal expression of E-cadh after epiboly stages. By combining 3D-deconvolution and segmentation of AJs in epidermal cells we were able to obtain a quantitative profile of E-cadh expression during normal epidermis morphogenesis from embryonic-to-larval life of zebrafish.

\section{Methods}

\section{Zebrafish husbandry}

Zebrafish strain of T/AB genetic background was used as wild-type. Male and female adults of 8-months-old were obtained from the Institute of Molecular and Cellular Biology of Rosario (IBR-CONICET-UNR), Argentina, and maintained at $28^{\circ} \mathrm{C}$ on a $14-\mathrm{h}$ light/10-h dark cycle. Adult fishes were kept in rectangular glass tanks of 12 liters at a density of (1-2 fishes/liter). In each tank, chlorine free water was constantly aerated and filtered (ATMAN hang On filter HF 0100), and renovated by $1 / 3$ twice a week, water temperature was maintained with a heater (Atman 200W). Water pH was kept between 7.8-8.2, salinity was maintained between 350-600 TDS and nitrates were controlled using biological films included in the filtering system. Fishes were fed twice a day with dried flakes (TetraMin) and twice a week with freshly hatched artemia cysts.

After breeding, laid eggs were collected and maintained at $28^{\circ} \mathrm{C}$. Then, embryos and larvae were staged according to Kimmel et al. ${ }^{23}$. Around 20 to 25 embryos were collected at $2.5,18,24,31,48$ and $72 \mathrm{hpf}$, then dechorionated and sedated with buffered tricaine methylsulfonate (MS-222, Sigma) prior to fixation. Approximately, 10-15 fixed embryos per stage were processed for immunofluorescence detection of E-cadh.

Adults and embryos were handled according to the ARRIVE guidelines and to the national guidelines from the Advisory Committee on Ethics of the Facultad de Bioquímica y Ciencias Biológicas de la Universidad Nacional del Litoral, Santa Fe, Argentina (Res. 229 and 388/2006).

\section{Embryos processing for immunodetection of E-cadh}

All embryos were fixed in toto in Carnoy solution at room temperature (RT) for at least $2 \mathrm{~h}$ and processed according to Izaguirre $e t a l .{ }^{24}$. Briefly, they were washed in PBS and permeated in $1 \%$ Triton X-100/PBS pH 7.4 for $1 \mathrm{~h}$. Then, washed in PBS pH 7.4 and incubated in normal goat serum (catalogue number: S-1000 Vector Laboratories, Burlingame, CA) for $45 \mathrm{~min}$, followed by overnight incubation with primary antibody 
anti E-cadh at $4^{\circ} \mathrm{C}$, three washes in PBS, and incubation with secondary goat anti-mouse IgG-FITC antibody at RT in darkness for $2 \mathrm{~h}$. Finally, they were rinsed in PBS and mounted in $50 \%$ Glycerol-PBS for microscopy imaging. Embryos directly incubated with secondary antibody and normal goat serum, were used as negative controls.

Antibodies. The 36/E-cadh monoclonal antibody recognizes the cytoplasmic domain of human E-cadh, regardless of phosphorylation status (clone 36 mouse $\operatorname{IgG2a}$, catalogue number: 610181 Transduction Laboratories). It was diluted 1:150 and revealed with secondary goat anti-mouse IgG-FITC antibody (Sigma, catalogue number: F8771, St. Louis, MO) used at 1:100 dilution.

\section{Microscope settings and image acquisition}

The spatial distribution of E-cadh in zebrafish epidermis was analyzed by fluorescence microscopy followed by image deconvolution and cell segmentation in 3D. The trunk was selected for the ease of orientation and image acquisition within the studied periods. Images were acquired with an inverted wide field sectioning microscope Olympus IX83 coupled to a digital camera CMOS-ORCA-Flash 2.8 (Hamamatsu), and commanded by Olympus Cell Sens software v. 1.13. Raw images were processed using FIJI v. 3.0. Sampling in xy was $0.182 \mu \mathrm{m}$ with Z-step every $0.33 \mu \mathrm{m}$. The epidermis was completely scanned along the trunk region. Exposure time was experimentally determined and fixed in order to avoid pixel intensity saturation and to minimize photobleaching.

\section{Deconvolution, intensity based segmentation of AJs and fluorescence intensity measurements}

Deconvolution was applied to restore fluorescence, which improved contrast and z-resolution, enabling better definition of E-cadh in $\mathrm{AJ}$ s for subsequent application of the 3D-segmentation tool. Quantification of E-cadh fluorescence intensity was carried throughout the epidermis bilayer $(\sim 6 \mu \mathrm{m})$ in calibrated 3 D-ROIs set at $2500 \mu \mathrm{m}^{2} \times 0.33 \mu \mathrm{m} \times 20$ slices $\left(16500 \mu \mathrm{m}^{3}\right)$. First, deconvolution was performed on individual 3D-ROI by applying Richardson-Lucy algorithm ${ }^{25}$ running under the open source Deconvolution Lab 2 v 2.0.0, with a theoretical point spread function $^{26}$. The Trainable Weka Segmentation Plugin v. 3.1.0, a classification tool based on machine learning in $\mathrm{FIJI}^{27}$ was applied on each deconvolved 3D-ROI so as to create a template that would automatically find the cell boundaries by providing trainable examples of membranes and cytosol (set as background). Each segmented 3D stack was further converted into 8-bit binary 3D-mask and multiplied by the corresponding deconvolved 3D-ROI to obtain the final "Result of Classification". On each classified image E-cadh fluorescence was quantified as the sum of pixel intensities per 3D-ROI and expressed as raw integrated density (RawIntDen). This measurement was performed on at least six 3D-ROIs per embryo to cover the trunk region, in five embryos per developmental stage. The pipeline for the image processing, theoretical psf and classifier model files are available as Supplementary File 1 as well as an example output (Supplementary File 1, Supplementary File 1).
Fluorescence intensity measurements in individual EVL cells On each classified image, 3D-ROIs of fixed volume $\left(10 \mu \mathrm{m}^{2} \times\right.$ $3 \mu \mathrm{m}$ deep) were selected along cell-cell contacts in EVL cells and fluorescence intensity was expressed as RawIntDen/cell-cell contact. To assess the fluorescence intensity in individual cells of the EVL, 3D-ROIs were manually outlined along cell perimeters to include the full membrane width and thickness and expressed as RawIntDen/cell area.

\section{Cell morphology and area measurements}

Cell morphology and cell area were assessed in EVL and EBL cells from previously selected 3D-ROIs. Round, 4-, 5-, 6-, 7- and 8 -sided cells were counted using the "polygon selection tool" in the individual layers. Mean area was expressed in the image calibrated units. Cell packing index was scored for the EVL and expressed as number of cells/ ROI area $\left(2500 \mu \mathrm{m}^{2}\right)$. Area of penta- and hexagonal cells from EBL and EVL were compared for all stages (Supplementary Supplementary File 2).

\section{Statistical analysis}

Five animals in the specified stages were obtained from three to five independent experiments. Differences in E-cadh levels between developmental stages were analyzed using a Linear Mixed Model (LMM). The assumptions of the model were checked graphically (linearity, homoscedasticity, normality of residuals and independence). The non-normality of the data was tested using the Shapiro-Wilk test. The variable "stage" was considered as fixed effects $(24,31,48$ and $72 \mathrm{hpf})$. The random effects of the model are the number of embryos per stage (5) and number of 3D-ROIs per embryo (at least 6). This number of ROIs per embryo was estimated in order to cover $>90 \%$ of the embryo trunk for the selected stages.

Differences in mean cellular area for the observed polygon types were analyzed using LMM containing the same fixed and random effects but adding the variable "morphology". The same statistical analysis was performed on the data set for the analysis of cell density and expressed as packing index (number of cell / ROI).

The Tukey's test was used for post-hoc pair-wise comparison when an effect or an interaction was found significant. Significant differences are denoted with $* \mathrm{p}<0.05, * * \mathrm{p}<0.01$. Data were analyzed with RStudio software's version 1.1 .453 and plotted with the BoxPlotR application or InfoStat software version 2018.

\section{Results}

E-cadh expression during embryonic epidermis morphogenesis

E-cadh expression pattern was determined in wild type zebrafish during epidermis development from 2.5 (blastula period) to 72 hpf. E-cadh protein was clearly detected in embryos at the blastula stage on epiblast cells (EVL) (Figure 1a). By 18 hpf, during primary organogenesis both epidermis layers are already established. At this stage, E-cadh was observed in AJs in EVL cells and weakly detected in EBL cells (Figure 1b-c). At later stages E-cadh labeling was observed as well as cytoplasmic dots, presumably in endocytic vesicles (Figure 1d). 

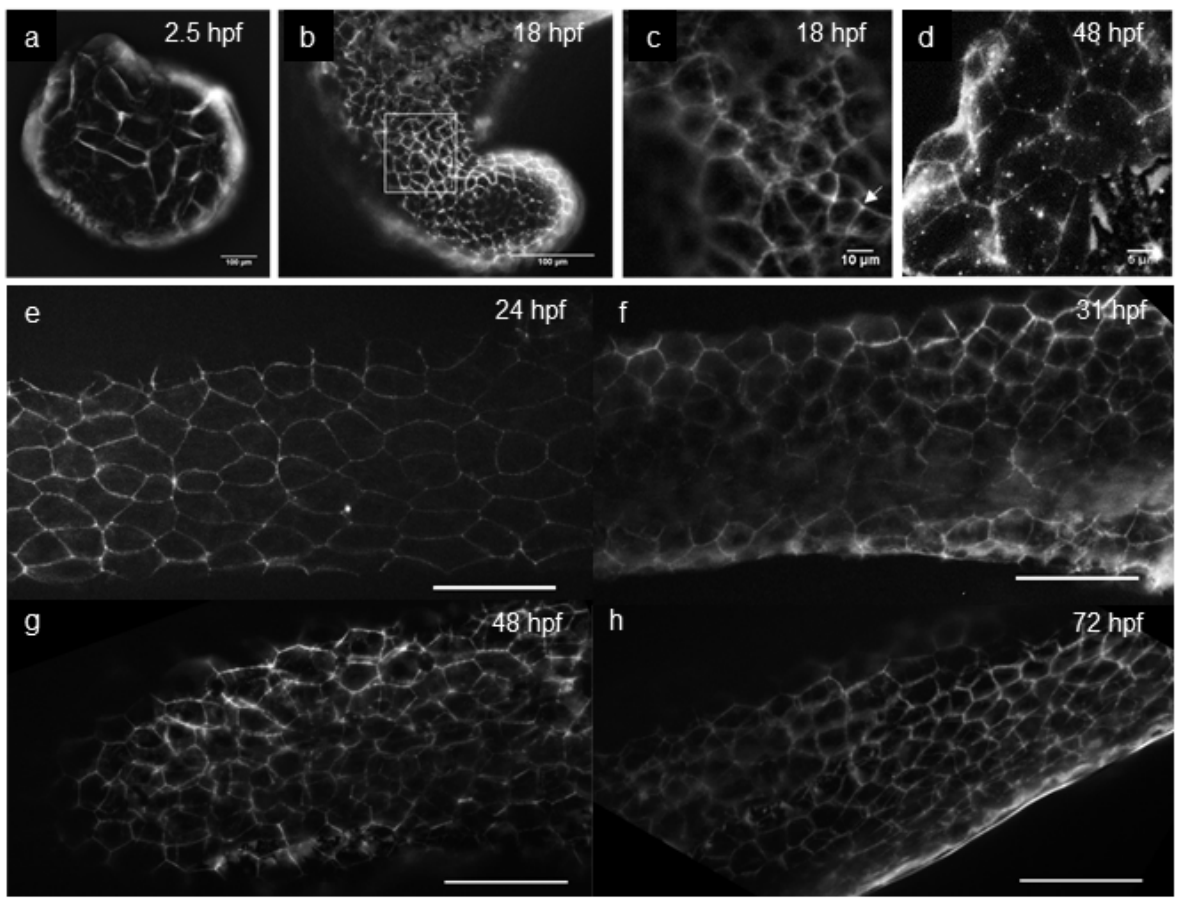

Figure 1. E-cadh immunofluorescence detection in zebrafish embryo epidermis. a) at 2.5 hours post fertilization (hpf) b) at $18 \mathrm{hpf}$; c) Zoom of selection in b); d) at $48 \mathrm{hpf}$, showing dot labeling in cytoplasm of enveloping layer (EVL) cells; e-h) 24 to 72 hpf embryos, displaying E-cadh membrane distribution in trunk, clearly visible in underlying EBL cells from $31 \mathrm{hpf}$. Images are contrast enhanced maximum intensity projections of 50 slices z-step: $0.33 \mu \mathrm{m}$. Objectives: UPLFLN 20X 0.75 NA and UPLFLN 40X 1.3 NA oil. Scale bar: $50 \mu \mathrm{m}$.

In embryos at $24 \mathrm{hpf}$, E-cadh labeling was observed in vertices (puncta adherens) as well as in micro-clusters along lateral cell-cell contacts in the EVL (Figure 1e). At $31 \mathrm{hpf}$ the underlying EBL was barely visible, detected as a faint E-cadh immunolabeling. From 48 hpf onwards, fluorescence in the underlying EBL cells was clearly detected (Figure $1 \mathrm{f}-\mathrm{h}$ ).

During the transition from embryo to larval stages the growing detection of E-cadh along cell-cell contacts parallels noticeable changes in cell size and morphology in the epidermis bilayer (Figure 1, e-h), which were further analyzed.

E-cadh levels were compared in the epidermis layers between stages 24, 31, 48 and 72 hpf, a period during which intense morphogenetic events lead to hatching and significant physiological changes occur for the resulting larvae epidermis to adapt to the aquatic environment. By implementing a 3D-Segmentation algorithm based on machine learning we were able to generate a mask to extract fluorescence intensity values along cell-cell contacts on 3D-ROIs covering the trunk epidermis bilayer and at each developmental stage (Figure 2a-d). With this approach we measured a significant increase of E-cadh levels between 31 and $48 \mathrm{hpf}$, consistent with the visible detection of E-cadh in the EBL and the visible increase in cell density in the EVL, which was subsequently quantitated.

\section{Cell geometry changes during embryo to larval transition}

Changes in cell shape, area and density were quantitated in an attempt to correlate the observed increments in E-cadh expression with cell morphology changes characteristics of developing epithelia ${ }^{28}$. Similar to the other epithelia, the morphogenetic processes leading to epidermis topology development involve cell morphology changes with a predominance of hexagonal geometry in the outermost layer ${ }^{16,24,28}$. Therefore, the distribution of the cell polygons classes was analyzed in the EVL layer. While round-cells, 4- and 8-side cell polygons were only detected in 24, 31 and 48 hpf stages and represented no more than 7, 15 and $2 \%$ respectively, pentagonal and hexagonal shaped cells predominated in all stages (Figure 3a). Hexagonal cells constituted approximately $34 \%$ of EVL total cells in stage $24 \mathrm{hpf}$ and $45-50 \%$ at 31,48 and $72 \mathrm{hpf}$ with a two-fold increase above pentagonal cells from $31 \mathrm{hpf}$. Hexagonal cells represented $\mathrm{a} \sim 50 \%$ of the total cells analyzed consistent with previous reports for other species ${ }^{14}$.

For all polygon types assessed in the EVL the mean cell areas decreased within the same polygon type groups from 24 to 72 hpf (Figure 3b). In the EBL, and despite fewer cells were accessible for area measurements, this tendency was not evident (Supplementary Figure 2). Therefore, the visibly increment in cell density in the EVL was characterized by an establishment of hexagonal cell morphology.

We hypothesized then, that the significant increment of E-cadh levels in the epidermis bilayer between 31 and $48 \mathrm{hpf}$ could reflect a contribution of the appearance of more cell-cell contacts per area, the addition of more protein to cell-cell contacts and the emergent detection of the protein in the underlying EBL. 

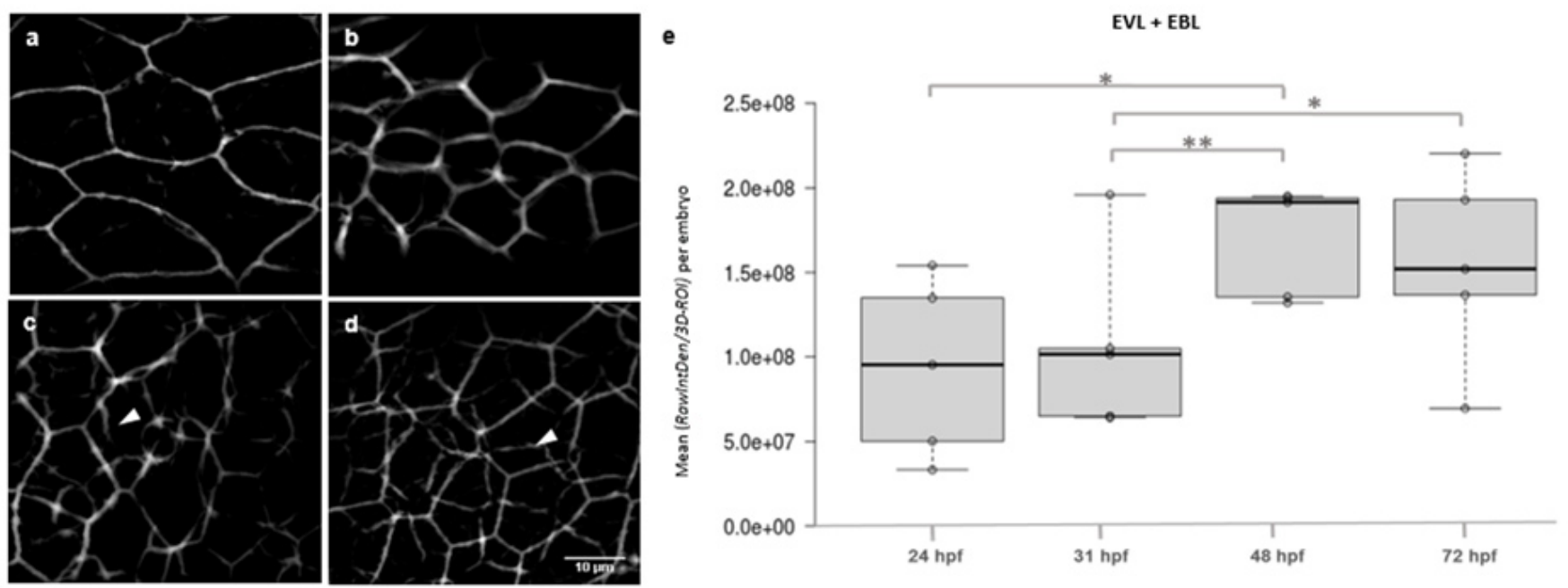

Figure 2. Expression patterns of E-cadherin (E-cadh) during epidermis development from stage 24-to-72 hours post fertilization (hpf). a) $24 \mathrm{hpf}$ and b) $31 \mathrm{hpf}$, with incipient E-cadh labeling of the underlying epidermis basal layer (EBL) cells; c) 48 hpf; d) $72 \mathrm{hpf}$, with stronger detection of E-cadh in the EBL (arrow heads). Panels are representative 3D-ROIs classified images shown as sum of intensities in projections of 20-optical section stacks covering the epidermis thickness (6.6 $\mu \mathrm{m})$; e) Box-plot of means of RawlntDen/ROI per embryo. Objective, 40X, NA 1.3 oil. Statistical significances, ${ }^{* *} p<0.01,{ }^{*} p<0.05$.
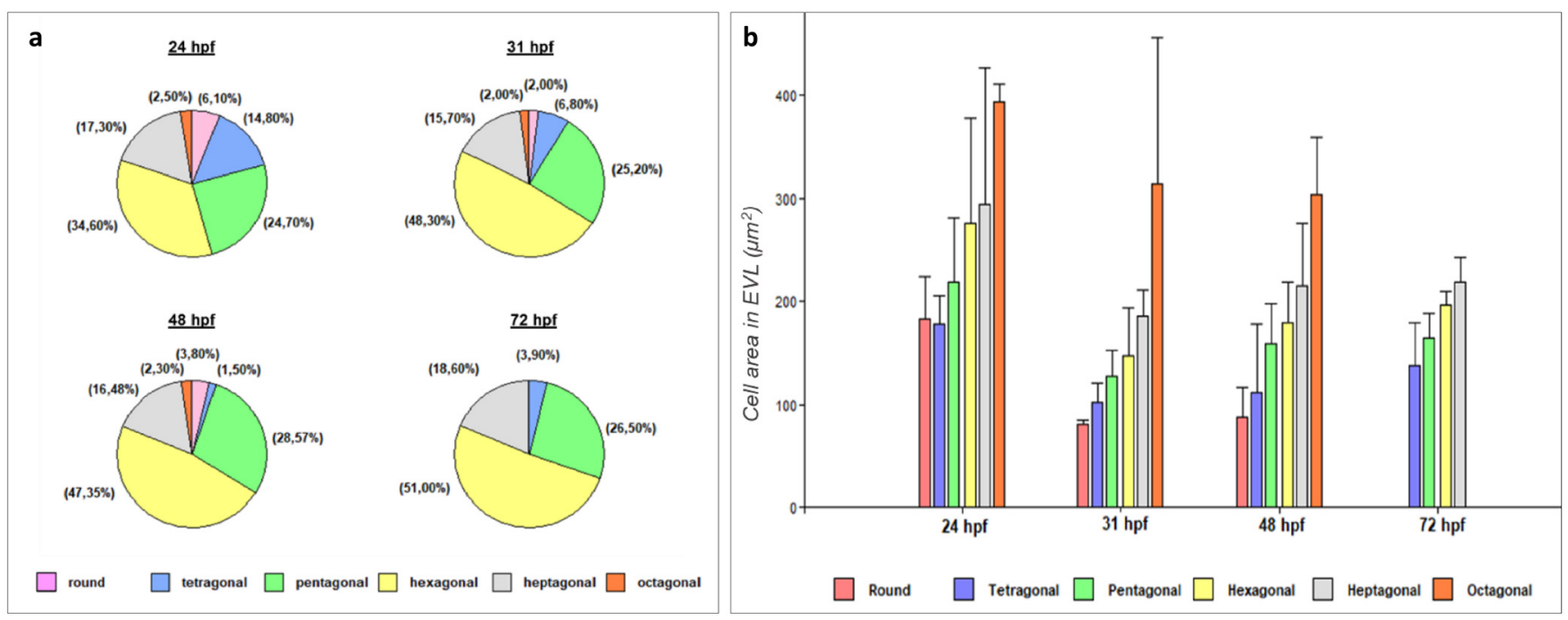

Figure 3. Polygon class distribution in the enveloping layer (EVL) layer from $\mathbf{2 4}$ to $\mathbf{7 2}$ hours post fertilization (hpf). a) Pie chart displaying percentages of $\mathrm{x}$-sided polygons of embryos at $24 \mathrm{hpf}$ ( $n=81$ cells), $31 \mathrm{hpf}$ ( $n=147 \mathrm{cells}$ ), $48 \mathrm{hpf}$ ( $n=133 \mathrm{cells}$ ) and $72 \mathrm{hpf}$ ( $n=102$ cells). Hexagonal and pentagonal cells are the main cell morphologies observed in the EVL. Data obtained from 30 3D-ROIs in five animals for each stage. b) Mean area of cell types on EVL at $24 \mathrm{hpf}(\mathrm{EVL} n=73), 31 \mathrm{hpf}(\mathrm{EVL} n=147), 48 \mathrm{hpf}(\mathrm{EVL} n=133)$ and $72 \mathrm{hpf}(\mathrm{EVL} \mathrm{n}=102)$.

The separation of the EVL as a sub-stack in individual 3DROIs is not completely free from the fluorescence contribution of the underlying EBL layer. Therefore, to evaluate the contribution of individual EVL cells to the observed differences in global fluorescence intensity, this was quantified in individual cellcell contacts of fixed volume (3D-ROIs, $10 \mu \mathrm{m}^{2} \times 3 \mu \mathrm{m}$ deep) in the EVL or in individual cells (Figure 4). With this approach overlapping contacts with the underlying EBL cells were excluded from the measurements. Mean RawIntDen values along cell-cell contacts revealed that more E-cadh may populate individual contacts during embryonic epidermis morphogenesis and contribute to the total fluorescence increase, although differences were not significant between developmental stages (Figure 4a). Then, to elucidate whether the increase of the protein between 31 and $48 \mathrm{hpf}$ could be due to the appearance of more cell-cell contacts per EVL area, cell density was estimated and expressed as a cell packing index (Figure 4b). However, this showed a two-fold increase in cell density by $31 \mathrm{hpf}$ without significant change at $48 \mathrm{hpf}$. Then, fluorescence intensity was quantified in individual cells of the EVL manually 

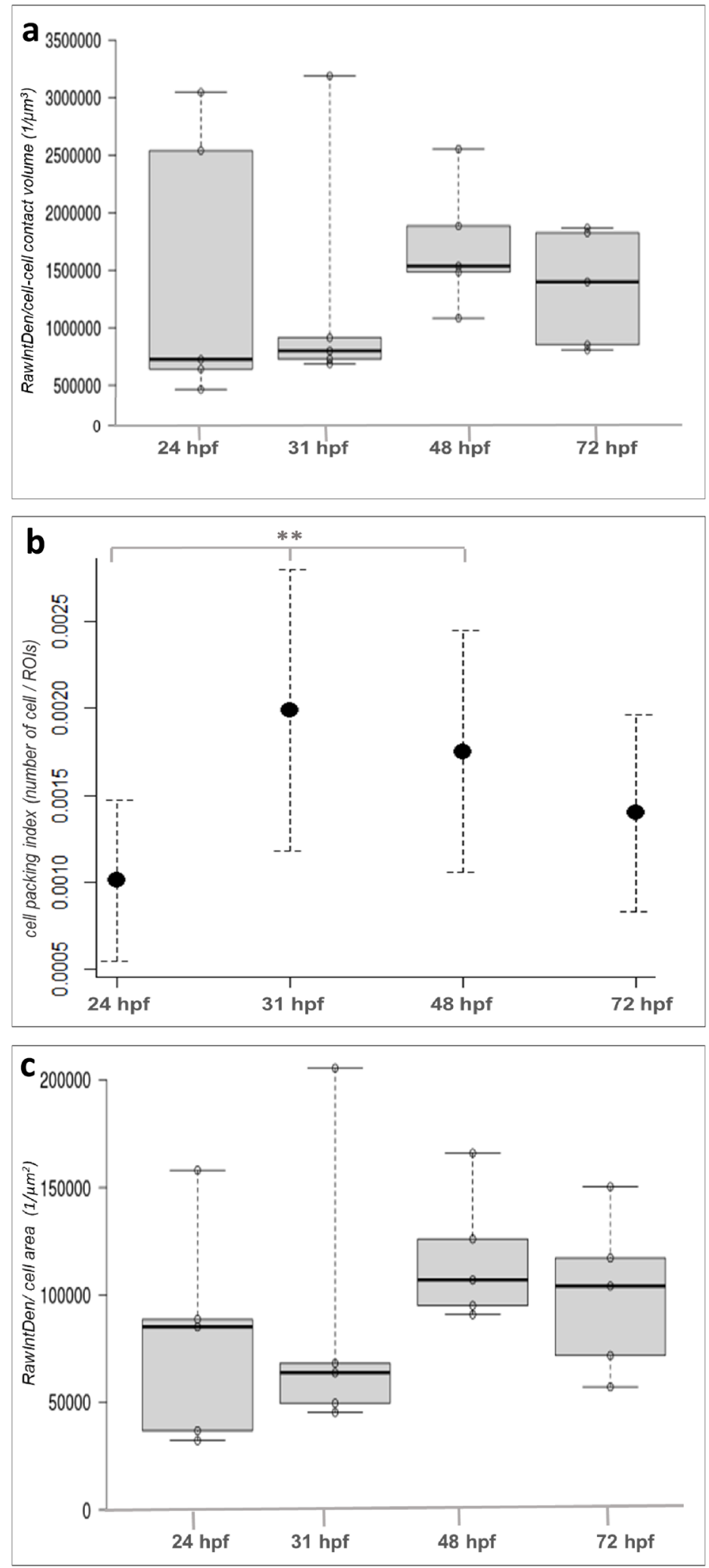

Figure 4. E-cadh expression profile in individual cells of the enveloping layer (EVL). a) Box-plot of RawlntDen/ cell-cell contact in the EVL; b) Plot of mean of cell packing index calculated as average number of cells per individual ROls $\left(2500 \mu m^{2}\right)$. Statistical significances, ${ }^{* *} \mathrm{p}<0.01$; c) Box-plot of means of RawlntDen/average cell area in the EVL. 
outlined from the original 3D-ROIs, and expressed as RawIntDen/ cell area (Figure 4c). As expected, the expression of E-cadh in the EVL followed a similar pattern as the one obtained for the global bilayer analysis. However, difference between 31 and $48 \mathrm{hpf}$ was not significant. Together this data suggested that the main contribution to the significant increase in E-cadh in the bilayer is due to the growing detection of the protein in the underlying EBL observed at $48 \mathrm{hpf}$.

\section{Dataset 1. Raw images for Figure 1 for 2.5 and 18 hours post fertilization (hpf). These can be viewed using FIJI or ImageJ}

http://dx.doi.org/10.5256/f1000research.15932.d217819

Dataset 2. Raw and processed images of 3D-ROls for assessing RawintDen, cell areas and cell morphology data for 24, 31,48 and 72 hours post fertilization (hpf) for Figure 2a and Dataset 3. Raw can be viewed using FIJI or ImageJ

http://dx.doi.org/10.5256/f1000research.15932.d217820

Dataset 3. RawIntDen, cell areas and cell morphology counts for Figures 2, 3 and 4

http://dx.doi.org/10.5256/f1000research.15932.d217821

\section{Discussion}

Epithelial architecture retains essential features such as apical/basal cell polarization, formation of cell-cell junctions, and the constitution of a paracellular diffusion barrier, all of which enable epithelia to serve a great diversity of biological functions ${ }^{29}$. The organization of mature epithelia into packaging of hexagonal shaped cells is a feature evolutionarily conserved ${ }^{14,30}$. This appears to be the optimum arrangement concerning the transduction of forces with minimum energy costs. The role of E-cadh in molecular architecture of epithelia has been studied extensively in animal tissues, partially owing to its decisive play in human cancers ${ }^{31}$. In frog and fish embryos, as in others, cadherins are the main adhesion factors responsible for regulating the shape of the embryo and its role has been thoroughly described during epiboly and gastrulation ${ }^{32-34}$. On established animal epidermis, E-cadh performs fine-tuned cellcell contact remodeling to maintain tissue integrity while the body axis elongates, this is characterized by modulation of cell shape, size and density to achieve the stable hexagonal arrangement ${ }^{28,35,36}$.

In zebrafish, the prospective epidermis is established at $24 \mathrm{hpf}$ as a bilayer formed by the enveloping layer (EVL) and the epidermal basal layer (EBL). Despite numerous descriptions about E-cadh role in epiboly and gastrulation, there is scarce information about E-cadh distribution in epidermis beyond this stage and during the embryo to larval transition. During this period body axis elongates from $1 \mathrm{~mm}$ at $24 \mathrm{hpf}$ to $3.5 \mathrm{~mm}$ at 72 hpf and embryos undergo hatching asynchronously between 48 and $60 \mathrm{hpf}^{23}$. Once in direct contact with water, the embryonic epidermis is the main protective barrier against pathogens. Therefore, we find it relevant to study the spatiotemporal distribution of E-cadh in zebrafish and elucidate a relationship between E-cadh levels, cell morphology and cell density in the epidermis bilayer from "embryos" to "larvae".

We implemented a trainable 3D-segmentation tool in $\mathrm{FIJI}^{37}$ to extract fluorescence intensity values from epithelial cells in in toto immunolabeled epidermis. Global expression was estimated from these 3D-segmentation volumes excluding cytoplasm (E-cadh in endosomal or in reticulo-endoplasmic compartments) in the bi-layered epidermis from embryo to larval stages. At present, only one pipeline method was reported for segmentation and tracking of epithelial cells based on the detection of the AJs in voxels in the Drosophila notum and leg epithelium ${ }^{38}$.

At the membrane level, E-cadh protein concentrates in clusters detected as puncta adherens in cell vertices or as lateral micro-clusters at $24 \mathrm{hpf}$, that turns into a continuous belt structure from stage $31 \mathrm{hpf}$ onwards, when intracellular E-cadh is also frequently observed in the cytoplasm of EVL cells.

Intensity based analysis showed that growing levels of E-cadh along cell-cell contacts during zebrafish epidermis development correlate with cell morphology changes towards hexagonal geometry. Specifically, within a short period between 24 and $31 \mathrm{hpf}$, a two-fold increase in cell density parallels the appearance of penta- and hexagonal cells together representing $\sim 75 \%$ of the polygons classes similarly to other animal models ${ }^{14}$.

Global bilayer analysis of E-cadh fluorescence intensity revealed a significant increase in protein expression between 31 and 48 hpf. In an attempt to establish the contribution of individual layers to the observed difference, the outermost EVL layer was analyzed by selecting individual cells or cell-cell contacts without the interference of the fluorescence coming from the basal layer.

Mean E-cadh levels measured in fixed cell-cell contact volumes of EVL cells showed a steady increase from 24 to 72 hpf, but without significant differences between stages. When E-cadh levels were estimated per average cell area in the EVL, a visible increase was observed between 31 and $48 \mathrm{hpf}$, although non-significant, indicating that the emergent detection of E cadh in the EBL from $31 \mathrm{hpf}$ onwards may indeed contribute to the significant increase in the protein levels measured in the epidermis bilayer.

We cannot overlook that during this embryonic period characterized body elongation, either cell proliferation or adherens junctions remodeling, through active E-cadh trafficking could account for the observed increase in cell density in the epidermis $^{39,40}$. These mechanisms has been well described for the hexagonal cell packing in the developing D. melanogaster pupal wing under polarized trafficking of E-cadh ${ }^{28}$ and should be further analyzed in vivo within this period in zebrafish.

As a novel outcome, a recent report proposed that tension generated by the E-cadh/AmotL2/actin filaments complexes plays a crucial role in developmental processes such as epithelial 
geometrical packing as well as generation of forces required for blastocyst hatching both in mouse and human ${ }^{35}$. In zebrafish, the hatching process is the result of combined enzymatic digestion of the chorion ${ }^{41}$ together with mechanical forces that drive the embryo out of the yolk sac in a similar way as observed for mouse and human blastocyst hatching. In the present work, a peak in E-cadh membrane level was detected in the epidermis around the time of spontaneous hatching. Therefore, it is conceivable, that cell morphology remodeling leading to hexagonally packed geometry followed by a significant increase in $\mathrm{E}$ cadherin may achieve high cell surface compactness and stiffness of the epidermis required for efficient mechanical disruption of the chorion.

\section{Conclusions}

The presented results show that during the establishment of embryonic epidermis in zebrafish growing levels of E-cadh protein correlates with increased cell density in the EVL and the establishments of new cell-cell contacts in the EBL more significantly between 31 and $48 \mathrm{hpf}$. This differentiated and compact epidermal tissue is most likely to support mechanical stress prior to hatching which starts around $48 \mathrm{hpf}$ when the embryo contacts for the first time the aquatic environment directly.

The combination of classical immunofluorescence, image deconvolution with intensity based segmentation in 3D offers a powerful tool to study the spatial arrangement of cell-cell adhesion proteins and cell morphology in bi-layered epithelia that can be applied to cadherin morphants, to other species or processes such as wound healing and re-epithelialization of the skin.

\section{Data availability}

Dataset 1: Raw images for Figure 1 for 2.5 and 18 hours post fertilization (hpf). These can be viewed using FIJI or ImageJ 10.5256/f1000research.15932.d217819 $9^{42}$

Dataset 2: Raw and processed images of 3D-ROIs for assessing RawIntDen, cell areas and cell morphology data for 24, 31,48 and 72 hours post fertilization (hpf) for Figure $2 \mathrm{a}$ and Dataset 3. Raw can be viewed using FIJI or ImageJ 10.5256/ f1000research.15932.d217820 $0^{43}$

Dataset 3: RawIntDen, cell areas and cell morphology counts for Figure 2-Figure 4 10.5256/f1000research.15932.d21782144

\section{Grant information}

This work was supported by the National University of Entre Ríos, Argentina [PID-UNER 6145].

The funders had no role in study design, data collection and analysis, decision to publish, or preparation of the manuscript.

\section{Acknowledgements}

We thank Juan Ignacio Etchart for technical microscopy assistance; Sebastián Graziatti, from IBR-CONICET-UNR, for valuable advice in zebrafish husbandry; and Luciana Erbes and Angel Zeitoune for valuable advice in image processing. We thank Dr. José Biurrum Manresa for critical discussion and assistance with statistical methods, and Prof. Dr. Victor Hugo Casco, for his great support to this research by providing all the necessary equipment and access to the microscopy facilities in LAMAE.

\section{Supplementary material}

Supplementary File 1: Image processing pipeline for E cadherin fluorescence intensity segmentation and quantitation in 3D-ROIs selected in the trunk epidermis

Click here to access the data.

Supplementary File 2: theoretical psf stack for image processing pipeline

Click here to access the data.

Supplementary Figure 2: Mean cell area of the main cellular types of the enveloping layer (EVL) and epidermal basal layer (EBL) of Danio rerio from 24 to 72 hours post fertilization (hpf) (EVL n=48; EBL n=21), 31 hpf (EVL n=108; EBL n=30), 48 hpf (EVL n=101; EBL $\mathrm{n}=47)$ and $72 \mathrm{hpf}(\mathrm{EVL} \mathrm{n}=79 ; \mathrm{EBL} \mathrm{n}=45)$

Click here to access the data.

1. Cauna $\mathrm{N}$ : The free penicillate nerve endings of the human hairy skin. $J$ Anat. 1973; 115(Pt 2): 277-88. PubMed Abstract | Free Full Text

2. Muroyama A, Lechler T: Polarity and stratification of the epidermis. Semin Cell Dev Biol. 2012; 23(8): 890-896.

PubMed Abstract | Publisher Full Text | Free Full Text
3. Warga RM, Nüsslein-Volhard C: Origin and development of the zebrafish endoderm. Development. 1999; 126(4): 827-838. PubMed Abstract

4. Chang WJ, Hwang PP: Development of zebrafish epidermis. Birth Defects Res C Embryo Today. 2011; 93(3): 205-214. PubMed Abstract | Publisher Full Text 
5. Slanchev K, Carney TJ, Stemmler MP, et al.: The epithelial cell adhesion molecule EPCAM is required for epithelial morphogenesis and integrity during zebrafish epiboly and skin development. PLoS Genet. 2009; 5(7): e1000563. PubMed Abstract | Publisher Full Text | Free Full Text

6. Reig G, Cerda M, Sepúlveda N, et al:: Extra-embryonic tissue spreading directs early embryo morphogenesis in killifish. Nat Commun. 2017; 8: 15431. PubMed Abstract | Publisher Full Text

7. Little SC, Mullins MC: Extracellular modulation of BMP activity in patterning the dorsoventral axis. Birth Defects Res Part C Embryo Today Rev. 2006; 78(3): 224-242.

PubMed Abstract | Publisher Full Text

8. Le Guellec D, Morvan-Dubois G, Sire JY: Skin development in bony fish with particular emphasis on collagen deposition in the dermis of the zebrafish (Danio rerio). Int J Dev Biol. 2003; 48(2-3): 217-231. PubMed Abstract

9. Cline A, Feldman SR: Zebrafish for modeling skin disorders. Dermatol Online $J$. 2016; 22(8): pii: 13030/qt4ws351w8. PubMed Abstract

10. Lee RT, Asharani PV, Carney TJ: Basal keratinocytes contribute to all strata of the adult zebrafish epidermis. Hogan B, editor. PLoS One. 2014; 9(1): e84858. PubMed Abstract | Publisher Full Text | Free Full Text

11. Hulpiau $P$, van Roy F: Molecular evolution of the cadherin superfamily. Int $J$ Biochem Cell Biol. 2009; 41(2): 349-369. PubMed Abstract | Publisher Full Text

12. Yoshida C, Takeichi M: Teratocarcinoma cell adhesion: identification of a cellsurface protein involved in calcium-dependent cell aggregation. Cell. 1982; 28(2): 217-224.

PubMed Abstract | Publisher Full Text

13. Harris TJ, Tepass U: Adherens junctions: from molecules to morphogenesis. Nat Rev Mol Cell Biol. 2010; 11(7): 502-14. PubMed Abstract | Publisher Full Text

14. Gibson WT, Gibson MC: Cell topology, geometry, and morphogenesis in proliferating epithelia. Curr Top Dev Biol. Elsevier; 2009; 89: 87-114. PubMed Abstract | Publisher Full Text

15. Ragkousi K, Gibson MC: Cell division and the maintenance of epithelial order. J Cell Biol. 2014; 207(2): 181-188.

PubMed Abstract | Publisher Full Text | Free Full Text

16. Theveneau E, Mayor R: Collective cell migration of epithelial and mesenchymal cells. Cell Mol Life Sci. 2013; 70(19): 3481-3492.

PubMed Abstract | Publisher Full Text

17. Petrova YI, Schecterson L, Gumbiner BM: Roles for E-cadherin cell surface regulation in cancer. Mol Biol Cell. 2016; 27(21): 3233-3244. PubMed Abstract | Publisher Full Text | Free Full Text

18. Izaguirre MF, Casco VH: E-cadherin roles in animal biology: A perspective on thyroid hormone-influence. Cell Commun Signal. 2016; 14(1): 27. PubMed Abstract | Publisher Full Text | Free Full Text

19. Babb SG, Marrs JA: E-cadherin regulates cell movements and tissue formation in early zebrafish embryos. Dev Dyn. 2004: 230(2): 263-77. PubMed Abstract | Publisher Full Text

20. Kane DA, Hammerschmidt M, Mullins MC, et al.: The zebrafish epiboly mutants. Development. 1996; 123: 47-55.

PubMed Abstract

21. Kane DA, McFarland KN, Warga RM: Mutations in half baked/E-cadherin block cell behaviors that are necessary for teleost epiboly. Development. 2005 132(5): 1105-16

PubMed Abstract | Publisher Full Text

22. Sonawane M, Martin-Maischein H, Schwarz H, et al.: Lgl2 and E-cadherin act antagonistically to regulate hemidesmosome formation during epidermal development in zebrafish. Development. 2009; 136(8): 1231-1240. PubMed Abstract | Publisher Full Text

23. Kimmel CB, Ballard WW, Kimmel SR, et al:: Stages of embryonic development of the zebrafish. Dev Dyn. 1995; 203(3): 253-310. PubMed Abstract | Publisher Full Text

24. Izaguirre MF, Larrea D, Adur JF, et al:: Role of E-cadherin in epithelial architecture maintenance. Cell Commun Adhes. 2010; 17(1): 1-12.

PubMed Abstract | Publisher Full Text

25. Fish DA, Brinicombe AM, Pike ER, et al.: Blind deconvolution by means of the
Richardson-Lucy algorithm. Journal of the Optical Society of America A. 1995 12(1): 58-65.

Publisher Full Text

26. Sage D, Donati L, Soulez F, et al:: DeconvolutionLab2: An open-source software for deconvolution microscopy. Methods. 2017; 115: 28-41.

PubMed Abstract | Publisher Full Text

27. Arganda-Carreras I, Kaynig V, Rueden C, et al:: Trainable Weka Segmentation: a machine learning tool for microscopy pixel classification. Bioinformatics. 2017; 33(15): 2424-2426.

PubMed Abstract | Publisher Full Tex

28. Classen AK, Anderson KI, Marois E, et al:: Hexagonal Packing of Drosophila Wing Epithelial Cells by the Planar Cell Polarity Pathway. Dev Cell. 2005; 9(6): 805-817.

PubMed Abstract | Publisher Full Tex

29. Tunggal JA, Helfrich I, Schmitz A, et al.: E-cadherin is essential for in vivo epidermal barrier function by regulating tight junctions. EMBO J. 2005; 24(6): $1146-1156$

PubMed Abstract | Publisher Full Text | Free Full Text

30. Li Y, Naveed H, Kachalo S, et al:: Mechanisms of Regulating Cell Topology in Proliferating Epithelia: Impact of Division Plane, Mechanical Forces, and Cell Memory. Connon CJ, editor. PLoS One. 2012; 7(8): e43108 PubMed Abstract | Publisher Full Text | Free Full Text

31. Petrova YI, Schecterson L, Gumbiner BM: Roles for E-cadherin cell surface regulation in cancer. Mol Biol Cell. 2016; 27(21): 3233-3244. PubMed Abstract | Publisher Full Text | Free Full Text

32. Zalik SE, Lewandowski E, Kam Z, et al.: Cell adhesion and the actin cytoskeleton of the enveloping layer in the zebrafish embryo during epiboly. Biochem Cell Biol. 1999; 77(6): 527-542.

PubMed Abstract | Publisher Full Text

33. Bruce AE: Zebrafish epiboly: Spreading thin over the yolk. Dev Dyn. 2016; 245(3): 244-258.

PubMed Abstract | Publisher Full Text

34. Schepis A, Nelson WJ: Adherens junction function and regulation during zebrafish gastrulation. Cell Adh Migr. 2012; 6(3): 173-8 PubMed Abstract | Publisher Full Text | Free Full Text

35. Hildebrand S, Hultin S, Subramani A, et al.: The E-cadherin/AmotL2 complex organizes actin filaments required for epithelial hexagonal packing and blastocyst hatching. Sci Rep. 2017; 7(1): 9540. PubMed Abstract | Publisher Full Text | Free Full Text

36. Lecuit T, Lenne PF: Cell surface mechanics and the control of cell shape, tissue patterns and morphogenesis. Nat Rev Mol Cell Biol. 2007; 8(8): 633-44. PubMled Abstract | Publisher Full Text

37. Arganda-Carreras I, Kaynig V, Rueden C, et al.: Trainable Segmentation: Release v3.1.2. zenodo. 2016. Publisher Full Text

38. Cilla R, Mechery V, Hernandez de Madrid B, et al.: Segmentation and tracking of adherens junctions in 3D for the analysis of epithelial tissue morphogenesis. PLoS Comput Biol. 2015; 11(4): e1004124. PubMed Abstract | Publisher Full Text | Free Full Text

39. Le TL, Yap AS, Stow JL: Recycling of E-cadherin: a potential mechanism for regulating cadherin dynamics. J Cell Biol. 1999; 146(1): 219-232. PubMed Abstract | Publisher Full Text | Free Full Text

40. West JJ, Harris TJ: Cadherin Trafficking for Tissue Morphogenesis: Control and Consequences. Traffic. 2016; 17(12): 1233-1243. PubMed Abstract | Publisher Full Text

41. Yamagami K: Mechanisms of hatching in fish: secretion of hatching enzyme and enzymatic choriolysis. Am Zool. 1981; 21(2): 459-471. Publisher Full Text

42. Sampedro MF, Izaguirre MF, Sigot V: Dataset 1 in: E-cadherin expression pattern during zebrafish embryonic epidermis development. F1000Research. 2018. http://www.doi.org/10.5256/f1000research.15932.d217819

43. Sampedro MF, Izaguirre MF, Sigot V: Dataset 2 in: E-cadherin expression pattern during zebrafish embryonic epidermis development. F1000Research 2018. http://www.doi.org/10.5256/f1000research.15932.d217820

44. Sampedro MF, Izaguirre MF, Sigot V: Dataset 3 in: E-cadherin expression pattern during zebrafish embryonic epidermis development. F1000Research. 2018. http://www doi. 


\section{Open Peer Review}

\section{Current Peer Review Status:}

\section{Version 1}

Reviewer Report 13 November 2018

https://doi.org/10.5256/f1000research.17400.r40062

(C) 2018 Marrs J. This is an open access peer review report distributed under the terms of the Creative Commons Attribution License, which permits unrestricted use, distribution, and reproduction in any medium, provided the original work is properly cited.

\section{James A. Marrs}

Department of Biology, Indiana University-Purdue University Indianapolis, Indianapolis, IN, USA

The manuscript by Sampedro et al. provides an interesting and useful contribution to epidermis development in the zebrafish. Cadherin adhesion is among the mechanisms that control epidermis development, and the authors contribute an initial description of cadherin adhesion molecule expression changes during epidermis maturation. The image analysis and cell shape changes observed will provide a starting point for additional studies. However, I have some concerns about the manuscript.

1. The monoclonal antibody that the authors used to examine E-cadherin was raised to human E-cadherin cytoplasmic domain sequences. This antibody cross reacts with cadherins in various species and with cadherin types other than E-cadherin. E-cadherin is probably the most prevalent cadherin in the epidermis but this was not shown. If other cadherins are expressed, then this antibody is likely to detect those cadherins too.

2. Flurorescence microscopy can be a useful way to measure protein expression, but several controls would be necessary to ensure that expression is being detected within the linear range of flurorescence detection. These controls were not evident, and expression was not validated with other approaches.

3. The authors state that the prospective epidermis is established at $24 \mathrm{hpf}$, but this prospective structure is established at neurulation, which occurs significantly earlier. Overall, this is a useful contribution to our understanding of cadherin adhesion activity during epidermis development.

Is the work clearly and accurately presented and does it cite the current literature? Yes

Is the study design appropriate and is the work technically sound? Partly

Are sufficient details of methods and analysis provided to allow replication by others? Yes 
If applicable, is the statistical analysis and its interpretation appropriate?

Yes

Are all the source data underlying the results available to ensure full reproducibility? Yes

Are the conclusions drawn adequately supported by the results?

Partly

Competing Interests: No competing interests were disclosed.

Reviewer Expertise: Zebrafish cadherin adhesion

I confirm that I have read this submission and believe that I have an appropriate level of expertise to confirm that it is of an acceptable scientific standard.

Author Response 05 Dec 2018

Valeria Sigot, Facultad de Ingeniería, Universidad Nacional de Entre Ríos, Oro Verde, Argentina

1-The monoclonal antibody that the authors used to examine E-cadherin was raised to human E-cadherin cytoplasmic domain sequences. This antibody cross reacts with cadherins in various species and with cadherin types other than E-cadherin. Ecadherin is probably the most prevalent cadherin in the epidermis but this was not shown. If other cadherins are expressed, then this antibody is likely to detect those cadherins too.

VS: We are aware of this, indeed the supplier states in the datasheet that this antibody has some degree of cross-reactivity to P-Cadherin. This cadherin is expected to be expressed in the skin, its presence has been reported in the basal layer of the epidermis in mice most prominently in hair follicles (Tinkle et al. PNAS 2008105 (40) 15405-15410;

https://doi.org/10.1073/pnas.0807374105).

In adult zebrafish, the presence of P-cadherin was screened through immunohistochemistry in regenerating blastema but without positive detection (Mateus et al.Development (2015) 142, 2752-2763 doi:10.1242/dev.119701.

We did test an anti N cadherin, Clone 32/N-Cadherin (cat. 610920 BD Transduction Lab) IgG1 and we observed only a dim membrane labeling in the eye (figure below).

2-Fluorescence microscopy can be a useful way to measure protein expression, but several controls would be necessary to ensure that expression is being detected within the linear range of fluorescence detection. These controls were not evident, and expression was not validated with other approaches.

VS: We understand your concern and we are aware of the limitations that quantitative microscopy has, so far our intention was to be accurate in measuring the change in protein expression than the amount itself of the protein at a particular stage.In the "methods" 
section we stated that all the acquisition settings were held equal for each 3D stack, but we will specify in the new version of the manuscript that lamp power was set at $6 \%$ and the exposure time set at $370 \mathrm{msec}$. With these settings we collected z-stacks with lower than desired contrast and counted on the improvement in SNR after applying the deconvolution algorithm. Under these conditions photo-bleaching of FITC could be neglected and the distribution of the available intensity levels for all embryonic development stages corresponded well to the linear dynamic range of detection of the CMOS-ORCA-Flash 2.8 (4500:1, calculated from the ratio of the full well capacity and readout noise). With our approach we aim to implement an image processing routine for extracting fluorescence intensity and cell morphology features in a bilayer with a single immunofluorescence and acquisition procedure, which can be applied as well to living embryos using a transgenic reporter protein in laboratories with limited equipment and resources.

3-The authors state that the prospective epidermis is established at $\mathbf{2 4} \mathbf{~ h p f}$, but this prospective structure is established at neurulation, which occurs significantly earlier.

VS: Certainly, we misused the term "prospective" to refer to the immature bilayered epidermis this will be corrected in the manuscript

Competing Interests: No competing interests were disclosed.

Reviewer Report 12 November 2018

https://doi.org/10.5256/f1000research.17400.r39783

(C) 2018 Muller M. This is an open access peer review report distributed under the terms of the Creative Commons Attribution License, which permits unrestricted use, distribution, and reproduction in any medium, provided the original work is properly cited.

\section{Marc Muller}

Laboratory for Organogenesis and Regeneration, GIGA-Research, University of Liège, Liège, Belgium

This paper represents a thorough microscopic analysis of E-Cadh expression, as detected by immunostaining, during zebrafish development in the two layers of epidermal cells.

Fig. 1: what does the white arrow in Fig. 1c point to? Also, weak detection in EBL cells is not so obvious at $18 \mathrm{hpf}$, maybe another arrow (head) would be helpful.

Fig. 2: Comparison of E-cadh levels between stages: how far can it be excluded that immunodetection by the antibodies may be systematically different at different stages, considering the important changes in the epidermal cells, especially between 31 and 48hpf (hatching)?

This comment also applies to Fig. 4, where in addition the differences between stages are either non-significant or dismissed by the authors.

Overall, this comment sheds some doubt onto the comparisons of intensities between stages, 
while the changes in topology (polygon classes) is more secure. I was wondering whether counting of the puncta adherens, independent of intensity, could be performed to further support the conclusions. Also, the weaker labelling of the deeper EBL layer would be further supported by performing immunodetection on sections.

Is the work clearly and accurately presented and does it cite the current literature? Yes

Is the study design appropriate and is the work technically sound? Partly

Are sufficient details of methods and analysis provided to allow replication by others? Yes

If applicable, is the statistical analysis and its interpretation appropriate?

I cannot comment. A qualified statistician is required.

Are all the source data underlying the results available to ensure full reproducibility? Yes

Are the conclusions drawn adequately supported by the results? Partly

Competing Interests: No competing interests were disclosed.

Reviewer Expertise: Zebrafish development, organogenesis and toxicology

I confirm that I have read this submission and believe that I have an appropriate level of expertise to confirm that it is of an acceptable scientific standard, however I have significant reservations, as outlined above.

Author Response 28 Nov 2018

Valeria Sigot, Facultad de Ingeniería, Universidad Nacional de Entre Ríos, Oro Verde, Argentina

Fig. 1: what does the white arrow in Fig. 1c point to? Also, weak detection in EBL cells is not so obvious at $18 \mathrm{hpf}$, maybe another arrow (head) would be helpful.

VS: The white arrow indicates a single puncta adherens in contacting EVL cells. Following your suggestion, an arrowhead will point the weak detection in EBL cells at 18 hpf.

Fig. 2: Comparison of E-cadh levels between stages: how far can it be excluded that immunodetection by the antibodies may be systematically different at different stages, considering the important changes in the epidermal cells, especially between 31 and 48hpf (hatching)? This comment also applies to Fig. 4, where in addition the differences between stages are either non-significant or dismissed by the authors. 
VS: If we understood your question, your concern refers to how we can explain differences in E-cadh expression whilst cells are changing in size and shape so distinctly between stages and in particular between 31 and 48 hpf.

Actually, between 31 and 48 hpf there is no significant increase in cell density in the EVL (Fig 4b), Thus, we exclude that the appearance of more cell-cell contacts per area (decrease in cell size and increase in the percentage of hexagonal cells) is the main contribution to the observed difference in E-cadh expression in the EVL. This is explained in the text, but probably the asterisks are misleading in figure $4 b$, (we will correct that in the new version). The graphs in Figure $4 a$ and c clearly show this "trend" in the increase in the expression level from 31 to $48 \mathrm{hpf}$, either by quantifying cadherin along fixed volumes of cell-cell contacts, or in individual cells of the EVL. However, this increment was not enough to account for the significant difference observed globally (EVL+EBL) thus we conclude that is the growing detection of E-cadh at the EBL which contributes to this difference between 31 and $48 \mathrm{hpf}$.

We did not dismiss the non-significant results shown in Figure 4 which are only for EVL. The Linear Mixed Model approach proved robust enough for our analysis based on intensity information.

Overall, this comment sheds some doubt onto the comparisons of intensities between stages, while the changes in topology (polygon classes) is more secure. I was wondering whether counting of the puncta adherens, independent of intensity, could be performed to further support the conclusions.

We understand your concern and we are aware of the limitations that quantitative microscopy has, so far our intention was to be more accurate in measuring the change in protein expression than the amount itself of the protein at a particular stage. Even though, as you propose it is more secure to extract morphological data or counting puncta adherens, our approach supported by the LMM statistical method, allows analysing larger areas of epidermis being more representative and descriptive of the tissue.

Also, the weaker labelling of the deeper EBL layer would be further supported by performing immunodetection on sections.

It is true, but we prefer to take advantage of the in-toto labeling and imaging of the whole mounted embryos maintaining as much as possible an intact epidermis. In addition, as we do not have the resources to label specifically the basal cells for instance with an anti p63 antibody, we used this differential analysis of the global (EVL+EBL) and the EVL to account for the contribution of the E-cadh expression from the EBL.

With our approach we aim to implement an image processing routine for extracting fluorescence intensity and cell morphology features in a bilayer with a single immunofluorescence and acquisition procedure, which can be applied as well for live embryos using a transgenic reporter protein in laboratories with limited equipment and resources.

Competing Interests: No competing interests were disclosed. 
Reviewer Report 24 October 2018

https://doi.org/10.5256/f1000research.17400.r39415

(C) 2018 Harris T. This is an open access peer review report distributed under the terms of the Creative Commons Attribution License, which permits unrestricted use, distribution, and reproduction in any medium, provided the original work is properly cited.

\section{Tony J. C. Harris}

Department of Cell \& Systems Biology, University of Toronto, Toronto, ON, Canada

This paper describes the distribution of E-cadherin and the packing of cells within the developing epidermis of the zebrafish embryo. From 24-72 hours post fertilization the total amount of Ecadherin detected at all cell-cell contacts of the epidermis was found to increase. Over this same developmental period, hexagonal cells seemed to become more prevalent while tetragonal, octagonal and round cells become less frequent. Other parameters were quantified but were found not to be statistically significant between stages of development.

A major concern with the analysis is the variability of the E-cadherin detection across the epidermis in single images (e.g. Figure 1e-h). The source of this variability was unclear. It was also unclear how the authors dealt with this variability for the quantifications.

The authors also noted "dot labeling in the cytoplasm" in panel 1d, but these puncta were not apparent in panel $1 \mathrm{~g}$ which displayed the same developmental stage.

Statistical tests were not applied to the analyses of polygon classes in Figure 3. Also it was not stated whether SD or SE bars are shown in Figure 3b.

Is the work clearly and accurately presented and does it cite the current literature? Yes

Is the study design appropriate and is the work technically sound?

Partly

Are sufficient details of methods and analysis provided to allow replication by others? Yes

If applicable, is the statistical analysis and its interpretation appropriate? Partly

Are all the source data underlying the results available to ensure full reproducibility? Yes

Are the conclusions drawn adequately supported by the results? Partly 
Competing Interests: No competing interests were disclosed.

I confirm that I have read this submission and believe that I have an appropriate level of expertise to confirm that it is of an acceptable scientific standard, however I have significant reservations, as outlined above.

Author Response 25 Oct 2018

Valeria Sigot, Facultad de Ingeniería, Universidad Nacional de Entre Ríos, Oro Verde, Argentina

This paper describes the distribution of E-cadherin and the packing of cells within the developing epidermis of the zebrafish embryo. From 24-72 hours post fertilization the total amount of E-cadherin detected at all cell-cell contacts of the epidermis was found to increase. Over this same developmental period, hexagonal cells seemed to become more prevalent while tetragonal, octagonal and round cells become less frequent. Other parameters were quantified but were found not to be statistically significant between stages of development.

A major concern with the analysis is the variability of the E-cadherin detection across the epidermis in single images (e.g. Figure 1e-h). The source of this variability was unclear.

VS: If I understand well, your concern refers to the variability of E-cadh detection between stages and as well within single images (in fig 1 panel e-h). In this figure, single images (stages) are displayed as maximum intensity projections of 50 optical sections, in addition, they are larger than the ROIs used for quantitation aiming to show the curvature of the trunk and changes in cell morphology and density. As stated in the legend, they are contrast enhanced for visualization purposes. For quantitation, these and other images acquired were processed following the protocol (Suppl. File 1) and displayed in Figure 2, each panel

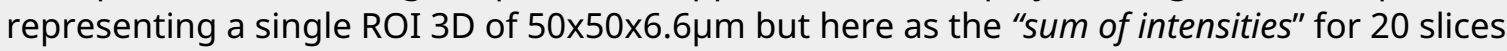
from which fluorescence intensity values were quantitated.

It was also unclear how the authors dealt with this variability for the quantifications.

VS: This was the main challenge of the approach because of the trunk morphology which changes during the studied period and the endogenous fluorescence of the yolk. Although the regions were selected at random along the trunk our criteria was to select the maximum ROI volume that cover a relatively flat region of the epidermis bilayer, with a minimum of 50 stacks including sections below and above the bilayer, to allow for proper restoration of fluorescence upon de-convolution and selecting regions from the yolk extension to the tail to minimize the contribution of the yolk fluorescence.

VS: The LMM (Linear Mixed Model) was employed to analyse the statistical differences of the quantitated intensity values between stages for the non-normal distribution of the data. This was selected as a suitable model to consider the variability of E-cadh detection between embryos within each stage. In this approach, the number of embryos per stage (5) and the 
number of ROIs/embryo (6) were set as a random effect and the stages (4) set as the fixed effect.

The authors also noted "dot labeling in the cytoplasm" in panel 1d, but these puncta were not apparent in panel $1 \mathrm{~g}$ which displayed the same developmental stage.

VS: I have already replaced the image for a more evident one, to show the E-cadh cytoplasmic dot pattern along the trunk at $48 \mathrm{hpf}$.

\section{Statistical tests were not applied to the analyses of polygon classes in Figure 3. Also it was not stated whether SD or SE bars are shown in Figure $3 \mathrm{~b}$.}

MFS: Figure 3 shows the distribution of all the polygon classes found in the EVL, in the studied stages. Although the pie chart displays the percentage of $\mathrm{x}$-sided polygons, this represents a qualitative observation of the results and as you suggest, it would be more convenient, to support our results, to make a bar graph showing the mean values per $\mathrm{n}$ with its corresponding dispersion measure (SD; Standard Deviation). It is intended to show that there are significant differences between the main classes of polygons found, applying the corresponding statistical tests.

MFS: It will be necessary to modify the legend of this figure, specifying that Figure $3 a$ corresponds to a bar graph displaying mean percentages of $x$-sided polygons of embryos at $24 \mathrm{hpf}(\mathrm{n}=81$ cells), $31 \mathrm{hpf}(\mathrm{n}=147$ cells), $48 \mathrm{hpf}(\mathrm{n}=133$ cells) and $72 \mathrm{hpf}(\mathrm{n}=102$ cells). The bars will represent mean values with their standard deviations. The type of statistical analysis performed on the data and the p-value obtained will be specified.

MFS: Regarding Figure $3 b$ this shows the mean area of cell types at $24 \mathrm{hpf}(\mathrm{EVL} \mathrm{n}=73$ ), 31 hpf (EVL $n=147), 48 \mathrm{hpf}(E V L n=133)$ and $72 \mathrm{hpf}(E V L n=102)$. In the same way, it will be necessary to complete this legend with statistical test applied, the obtained p-value and indicate that the bars represent cell mean area and its standard deviations (SD). All the data to build these figures were obtained from 30 3D-ROIs in five animals for each stage. The excel sheet that shows all these values (mean \pm standard deviation) and the new Figure 3 will be completed and uploaded in "data availability" section.

Competing Interests: No competing interests were disclosed. 
The benefits of publishing with F1000Research:

- Your article is published within days, with no editorial bias

- You can publish traditional articles, null/negative results, case reports, data notes and more

- The peer review process is transparent and collaborative

- Your article is indexed in PubMed after passing peer review

- Dedicated customer support at every stage

For pre-submission enquiries, contact research@f1000.com 